\title{
METHODOLOGICAL DISCUSSION OF INSERTION AND EXPORTATION OF LCA DATA EMBEDDED IN BIM ELEMENTS
}

\author{
CRISTIANE BUENO \& MÁRCIO MINTO FABRICIO \\ Institute of Architecture and Urbanism, University of São Paulo, Brazil
}

\begin{abstract}
The Life Cycle Assessment (LCA) methodology can be used to quantify, in the design phase, the impacts of a product throughout its life cycle and to determine which building components have the highest potential impacts. However, such a method has often been avoided due to the need for detailed input data and the complexity of the available tools. For that reason, although LCA is increasingly present in the construction sector demands, professionals continuously pursue new ways to incorporate such methodology to the building design and construction processes, as simple and uncomplicated as possible. A promising possibility is the incorporation of building systems LCA data in the BIM software tools. Numerous limitations of BIM-based LCA have been identified over the years. For instance, the complexity of LCA software tools, particularly as regards the data input and interpretation of results, and the interoperability issues, all need to be overcome. Once BIM models are composed of smart objects, which represent construction elements with encapsulated intelligence, they are expected to be where LCA data could be applied. In this paper a conceptual and methodological discussion will be developed on the practical possibilities of inclusion and export of LCA data embedded in BIM elements, focusing on Autodesk Revit software and its features. Such a discussion will take place by exploiting technological possibilities of such software and evaluating the possibilities of development and modification of parametric elements and families, as well as the further export potential of such embedded LCA information. The main goal is the construction of a robust theoretical framework that will precede the future development of a methodological BIM-LCA integration tool by the exploitation of the features available in the existing software.
\end{abstract}

Keywords: environmental assessment of buildings, life cycle assessment, building information modelling, BIM-LCA integration tools, functional unit.

\section{INTRODUCTION}

Early design stages decision-making is significantly determinant to a building's environmental impact mitigation. Building's life-cycle impact can be strongly reduced by choosing materials with low embodied impacts at such early design stages [1], [2].

However, there are so many decisions to be taken by the building designers during these stages and typically lack knowledge on which decisions are most impacting to a building's environmental performance, often leading designers to postpone decisions to later stages of the design process [1].

The challenge then, as identified by Brahme et al. [3], is to develop new methods for application of detailed analysis tools even during the early stages of building design when many of the variables for the building's technical sub-systems are not yet specified, and to provide the designer with quantitative analyzes and predictions of the building's performance [3]-[5].

Regarding such early stage design work, several researches have tried to integrate Building Information Modelling (BIM) software with Life Cycle Assessment (LCA) methodology and environmental optimization techniques in order to minimize buildings' potential impacts. Thus, LCA has also been used to estimate impacts of buildings at the early 
design stages and to enable better early decision-making by providing feedback on the environmental impacts BIM model design choices [1].

The brand-new approaches to the design, construction and maintenance of buildings in the construction industry needs an integrated collaboration for sustainable projects, which can be enabled by BIM applications. A sustainable-integrated design process simplifies the certification process in terms of time and cost, since early stage interactions and decisionmaking are possible, providing improved outputs. As the advantages of BIM are spread among building design professionals, they will play a more significant role in environmental performance throughout whole building life cycle [5].

\section{GOAL}

The aim of this study is to develop a theoretical review of the integration of LCA information within BIM platform and discuss the possibilities towards the insertion and exportation of LCA data embedded in BIM elements.

\section{METHODS}

This paper is based on a conceptual theoretical method, once it discusses the theoretical background for the maturity of implementation of LCA and BIM framework, and its main integration applications. A theory is an interrelated set of constructions made up of propositions or hypotheses that specify the relationship among variables. The systematic view may be an argument, a discussion or a justification, which helps to predict phenomena occurring in the world [6].

Moreover, such conceptual background is taken as a basis for the development of a new theoretical approach towards the implementation of reproducible LCA data into BIM platform, throughout qualitative discussion and some examples on BIM software tools.

\section{RESULTS AND DISCUSSION}

The barriers in applying LCA to the AEC industry have been identified by previous research, including obtaining environmental impact data for building products, tracking material flows, and defining system boundaries [7]-[9]. In addition, despite being increasingly used by building designers to digitally represent a facility since the early design stages, BIM currently lacks interoperability with LCA tools and software [10].

In order to turn LCA on an effective early stage decision-making tool for the construction industry, building designers must be better enabled to interpret environmental indicators' results and understand which material and design decisions most significantly determine a building's environmental impact and which choices are less important. Such knowledge must be part of an integrated BIM-enabled environmental impact assessment process, whereupon designers may focus on decisions with larger impact during the early design stages and postponing decisions with marginal impacts to latter design stages [1].

The literature review identified some studies focusing on the state of the art of BIM for sustainable design and construction. A survey applied by McGraw-Hill Construction for 2010 Green BIM Study [11] was conducted with a group of building industry professionals who use BIM tools to help achieve sustainability and building performance goals, and the provided results show that BIM is considered an essential tool, expected to be in extensive use in the near future for sustainable-aimed design. Larger use of green integrated design is also highlighted in other research as one of the key areas of potential growth for Green BIM [5].

Wang et al. [12] integrated BIM, LCA, energy analysis, and optimization software tools in order to evaluate the potential of environmental impact of several early stage building 
design parameters by using a multi-objective genetic algorithm to identify Pareto optimal solutions for cost minimization and environmental impact performance, what resulted in a notable reduction in global warming potential. Hauglustaine and Azar [13] presented a computational integration method for performing BIM energy performance assessments since to the sketch design phase, which included a limited number of design variables related to building's geometry and thermal performance. Such research applied a genetic algorithm to optimize cost and energy performance, and a sensitivity analysis to identify the relations between performance characteristics and design variables. Coley and Schukat [14] integrated BIM and thermal analysis tools in a method for early stage building designs optimization towards energy performance, which gives designers the possibility to choose from a set of designs based on non-optimized criteria.

The research of Basbagill et al. [1] also shows the importance of making a choice for one building component over another, arguing that designers often have the intuition on which decisions usualy achieve significant embodied impact reductions. Thus the proposed method allows designers to focus major efforts during the early design stages on decisions that are most likely to decrease a building's life cyle embodied environmental impact. By deferring material and design decisions related to smaller reductions to the latter design development stages, designers would avoid expending effort on low-return decisions during the early design stages.

Since BIM provides the possibility for superposing the multidisciplinary information within powerful models, its growing importance is combined to the increased demand for green certification, and BIM is expected to become an indispensable tool for sustainable design and construction. However, the studies related to sustainability concept vs BIM platform indicate that there is still a gap for integrated solutions, especially regarding the whole certification process. Among the barriers to full integration, the most proeminent are the lack of functional tools and the complex structure of the existing ones [15], [16]. Thus, it is important to develop a supporting method which facilitates the sustainable project decisions provided by BIM software for an integrated BIM and environmental data model [5].

The presenting authors have already built a survey on the available tools for BIM-LCA integration on a previously published research, pointing their features and major limitations [17]. The approached tools by [17] were Autodesk Green Building Studio, Elodie, eToolLCD, Lesosai, LCADesign and Tally, however, new tools were also recently lauched as Green building assessment tool (GBAT) [5], IESVE Impact Compliant Suite and One Click LCA, for instance. The currently available tools still have many barriers to overcome in order to be practally applied by planners, designers and investors. Such tools are considered to be difficult to handle, requiring a certain level of expertise and lots of comprehensive data in order to come to an applicable result, along with being overly time demanding for the decision stage. In order to empower design and construction of environemtal-efficient building facilities, it is necessary to develop design-centred methods and tools for integrated LCA, which are easily applicable in the early design stages [16], [17].

Other importante initiatives in continuous devepment are the BuildingSMART Data Dictionary (BSDD) [18] and the Product Data Templates (PDTs) [19]. Both of them aim at the standardization of common best practices and development of interoperable BIM embbeded data and may also support the spreading of the environmental data incorporated into BIM objects.

The BSDD [18], or IFD (International Framework for Dictionnaries) library, is a data dictionary that that, aside from translating the definitions to a given language, also links them to the concept it is supposed to identify, in order to improve interoperability in the 
construction industry. Thus it also provides context to BIM objects. Differently, the IFC library operates like a normal dictionary, where you can search by name, and a list of results will be presented. Such results are presented with full names in multiple languages, definitions and comments.

The IFD library is still under development and therefore the content is still limited, and it can be used free of charge. It is also possible to integrate it in your software, but that is a payed application [18].

In parallel, the PDTs are a resource under development for the building industry to solve the problem of creating customised data sets for prospective customers. A PDT is a standard questionnaire for each buiding equipment type. Each PDT aims to anticipatelly collect the information needed by the designer - from specification through operations to decommissioning and replacement.

PDTs are written in Excel format and are usable within all BIM platforms in order to avoid the need to grapple with multiple versions BIM software. When a manufacturer completes a PDT it becomes a Product Data Sheet (PDS), i.e., a 'digital' description of the product. The manufacturers are free to use the PDS in any library they choose, and they remain responsible for the accuracy and completeness of the provided PDS data.

These latter two initiatives, namely BSDD and PDTs, are not mainly focused on environmental assessment information, however they can work as facilitators in the incorporation and interoperability of environmental data between manufactures and BIM tools users.

Among the challenges of implementing LCA-based environmental assessment methods in the construction industry, the subjectivity and uncertainty inherent to the inventory data collection, the complexity of the functional unit and how those influence the viability of methodology application can be highlighted [17].

The functional unit definition - that is often hard to be handled in isolation from other building functions in order to evaluate building materials individually - is the first big challenge to be overcome. Moreover, there are also the regional and temporal characteristics of the production processes, that make the data collection still more complex and full of uncertainties [20].

LCA in construction is most frequently applied for the environmental performance improvement of building materials, and detailed environmental impacts assessment along the phases of manufacturing, construction, operation and end-of-life has been carried out for specific materials [16]. LCA studies are often used to support comparisons among different construction products with similar functions or among different systems that provide the same service. In order to ensure a fair comparison, it is fundamental that those systems to be compared provide the same function, since it is the prime basis of comparison in LCA studies. There is no LCA comparing objects or products, and any LCA study should be based on a functional unit, so that different products and services that provide the same function can be compared [21].

Building materials have an specificity since they do not usually provide the same functions and applications on a building [22]. Often there is no clear separation of functions and performance among individual technical requirements of a construction product. Once any product is part of the building's life-cycle as a component, one has to choose to allocate certain flows to the product or to the building system [23].

The comparison among building products with the same functional unit is limited to a few exemples, in the majority of cases, building products cannot be considered as alternatives for decision-making. The first set of building products which can be an alternative to the decision-making problem are the building components, therefore, the building component 
scale will be the best for taking comparisons, in most of the cases. For instance, a non-load bearing wall that can be built with several sets of materials represents a building component, and each wall has the same functional unit [22].

As the purpose of inserting LCA data in the BIM platform is providing quantitative environmental information to support environmental-based decision-making on building components, the functional unit should be as defined as possible, and needs to be precise enough to ensure accurate results. If the functional unit is set properly, it can be used for the assessment of the same building components in different buildings. For this reason, the building components should be considered independently, each as a isolated function, so the potential impact on the life cycle of any building component should not interfere with other ones [20].

The accurate definition of the system boundaries is important for the understanding of the modelled system and how it should be understood in a broader context. The flows that run through the product system boundaries sould be only elementary and product flows, i.e. input and output flows should be traced back to the way out of technosphere and become part of the environment [21].

Quantitative survey is an essential component of the LCA of building emissions, and needs both a high degree of knowledge and highly developed deployment skills to enable an accurate interpretation of designs and numerical representations of component quantities [24]. Because traditional computer-aided design software cannot store the additional information to ease the automatic calculation of building components parameters, quantity surveying has always been a manual and highly time consuming process, vulnerable to errors [24]. However, BIM platform has changed that scenario, since after the densities of various materials are entered into such software, it can perform an automatic statistical analysis on the quantities of the main building materials [24].

It is importante to mention that building components environmental properties shoud be presented as impact potential indicators, after the impact characterization performed in a LCA study. This is because the raw inventory data may lead the user to misleading conclusions, since different substance emissions have different characterization factos for impact potentials [20].

Antón and Díaz [25] have discussed the possible approaches for LCA data insertion within BIM platform, and have presented the advantages and limitations of them. The first approach would be the direct access to the BIM model information to calculate the LCA performance, which consists in extracting data directly from the BIM model, using an interoperable IFC format, and inserting it in a LCA software. Such approach has the advantage of avoiding data reentering, however as the LCA is not developed within the BIM software, there are still large interoperability issues and, moreover, any changes in the BIM model will demand the re-importing of LCA data to the dedicated software, what can be highly work and time demanding [25].

The second approach proposed by [25] would be the inclusion of environmental properties in the BIM objects, which consists of including environmental properties based on LCA calculations directly within BIM objects, so lists can be extracted from the models comprising neointimal quantities for the applied constructions materials, as summarized by [17] in the Fig. 1. Such approach is easier and faster and set environmental criteria highlighted for decision-making. Nevertheless, it is still necessary the improvement of available information on construction materials as there are unsolved issues regarding automatically inclusion of information related to transportation, location and regional characteristics of the project [25]. 


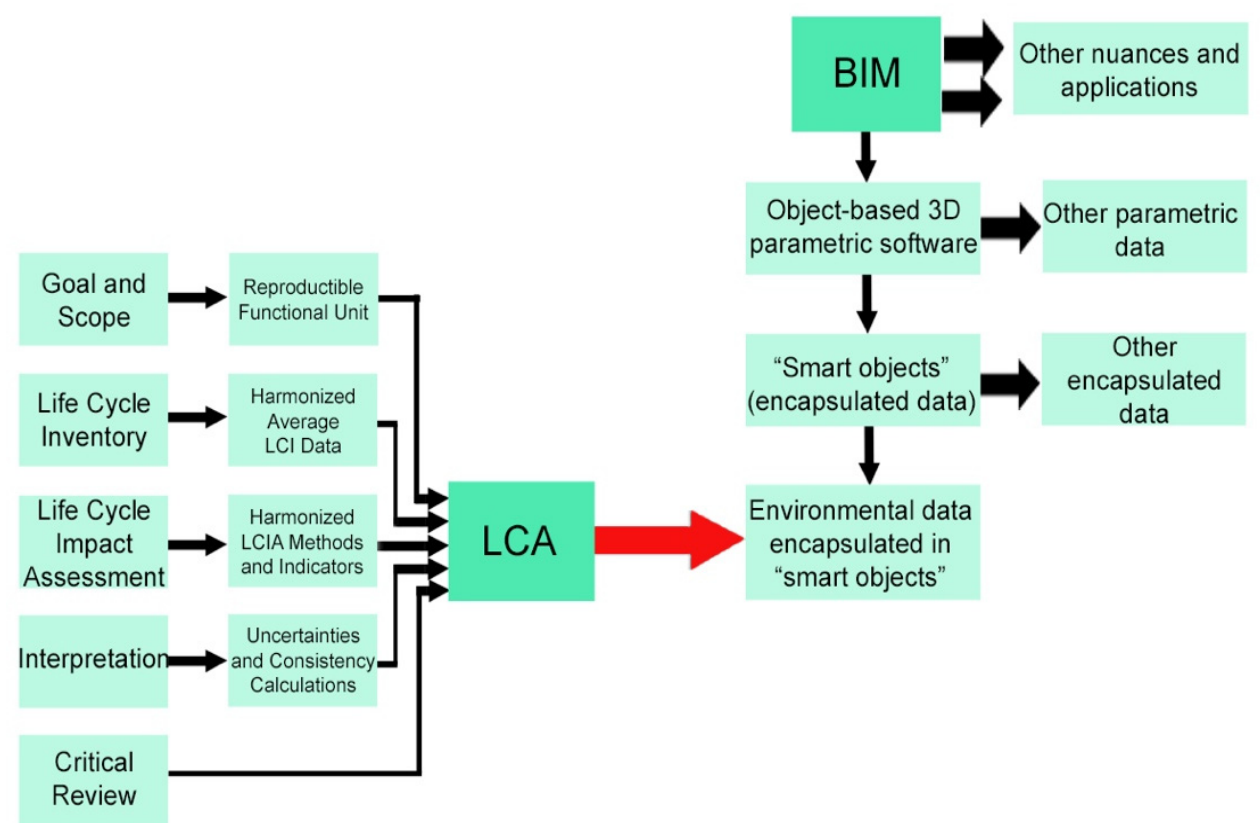

Figure 1: LCA implementation in BIM platform. (Source: [17].)

This latter approach is considered by this research to be the most promising one, since it allows the accomplishment of studies of LCA without the necessity to leave the BIM environment, and without the need for any additional software, since it is possible that the data are inserted directly into BIM objects, and exported to existing traditional spreadsheet software in quantitative form, not requiring any new skills or experts.

The environmental parameters to be inserted in the BIM platform could, for instance, be compatible with the format established for the Environmental Product Declarations (EPDs), so that the database can be fed automatically by these documents and directly by the producers of construction materials and components. Moreover, previously described tools as the BSDD and PDTs would be strongly useful to make such data standardized and internationally interoperable. This would make the process of producing environmental data more dynamic and up-to-date, and, moreover, as accurate as possible for the products applied to a specific project model.

BIM-enabled tools developers have the benefit of making their products available for researchers and other users to develop prototypes to run as plug-ins, however, such facility in BIM implementation is yet to be fully explored. Researchers must take advantage of such opportunity for developing news methods to quantifying the sustainability of design solutions to inform conceptual design decisions, as an integral part of BIM [26].

Therefore, it is important that building designers are capable to interpret environmental information in order to be able to compare alternatives and make choices during the design process. According to a previous research of the present authors [17], the conclusion of an action research for the evaluation of one of the most prominent BIM-LCA existing tools was that, despite the simplifications and friendliness inherent to such evaluated application, users had significant difficulties in interpreting the LCA results. Such a conclusion shows that, in 
parallel to the development of methods and tools for simplified application of LCA in the building design process, it is also necessary to invest in education and awareness strategies regarding the knowledge on the LCA methodological principles and scientific background [17].

Beyond the construction of knowledge for the correct use of the available LCA data, it is important that a routine is developed for automatic insertion and exportation of environmental data encapsulated in BIM objects. Based on the literature review developed in the present paper, as well as the research work previously developed by the authors [17], [20], it is noted that, in addition to the innumerable possibilities of new applications development, it is also possible to use traditional existing tools. Therefore, it is important to differentiate the actors involved in the processes of data input and output.

Data entry on the BIM platform should not be a building designer competence, since such professional often does not have the previous knowledge and the necessary domain of all the variables involved in the collection and manipulation of such environmental data. Data collection and input into BIM platform should be performed by LCA ad-hoc professionals, who have in-depth knowledge on the productive process of the analyzed construction components. Moreover, data entry must be performed together with the building components producers, making their products' environmental data available (more likely in EPD format) to building designers who want to use them in their projects. All the most complex calculations and characterization of life-cycle impacts should be concentrated at this stage of the process, so that the environmental data gets ready and simplified to the final user, i.e., the building designer.

The data output, i.e. the extraction of environmental information embedded in the model, should be simplified enough to be fully manipulated by the building designer without the need for third part specialized support. Yet, as stressed above, it is necessary that designers are minimally trained to interpret such environmental information in order to turn them into practical decision-making. However, it is important that, once the LCA results are extracted, there is no need for any further data processing by the designer, since the excessive complexity makes the environmental assessment too time- and effort-demanding, often leading to the abandonment of the use of such assessment method during the design process, especially in the early stages.

Thus, the intervention of LCA specialized professionals is needed, but it can be implemented prior to the building design process itself, avoiding an exacerbated consumption of designers' time and effort, and making possible the application of the methodology and the use of its data for decision-making.

It is important to emphasize that, for the development of the proposed method, it is not necessary (although it can be likely and beneficial as a process facilitator) the development of new tools or software, being possible to dispose of the collection of existing computational programs, such as comprehensive LCA software, spreadsheet and diagram development programs, and BIM programming and modelling software.

\section{CONCLUSION}

The conclusions based on the discussion of the literature review point to two preponderant limitations in the simplified tools: discrepancies in the final results of the LCA studies, leading to divergent conclusions, due to the software simplifications and assumptions; Difficulties identified by the users to estabilish connections between the databases, due to the lack of previous knowledge on the LCA methodology, which can lead to specification mistakes and, consequently, incorrect results. 
In view of such findings, this research concluded that in order to ensure the quality and robustness of the LCA results and to facilitate their implementation since the early design stages, an effective solution would be the prior insertion of the environmental data directly into BIM smart objects, i.e., BIM families must comprise the environmental impact data in their parametric information, so that the user can automatically perfome such environmental simulations by inserting those families into the model.

Thus, the specific environmental data for each family can be developed previously, for instance, by construction products manufacturers, favoring the construction and consolidation of building products databases, and ensuring the quality and robustness of the available data. International tools continuous under improvement as the BSDD and PDTs could comprise the environmental data within their BIM objects' libraries, becoming strongly useful to facilitate the international standardization and interoperabilization of the stages of collection, insertion and spreading of LCA data within BIM platform.

Regarding the proposes on the possibilites of outputs presentation and interpretation, in order to facilitate the visualization and analysis of the impacts from different alternatives by the user, a routine could be developed for exporting such environmental parameters to a pre-elaborated worksheet of a traditionally used software, which could automatically generate simplified graphics on the environmental impact potentials identified in the analyzed model. That would work on the same basis and format of PDS digital documents, so the user do not need to $b$ aware of many diferente methods or formats to work in.

Therefore, by using consolidated software tools and pre-existing knowledge in the different fields involved, it is possible to integrate LCA data directly into the BIM environment. This paper proposes the development of LCA studies by specialized professionals or the manufacturers themselves in dedicated software such as $\mathrm{GaBi}$ or Simapro, the data insertion and extraction of results by traditional software such as Excel, through the automated importation and exportation of information by currently used BIM software such as Revit or Archicad, for example.

It is important to note that the proposed approach has major challenges and potential limitations to be addressed and overcome, pointing to the need for a research effort to develop such routines and features, and how to deal with parametric issues related to the building materials transportation and end-of-life data.

The present article contributes to the body of knowledge of the area since, through the presentation of the state of the art of the BIM-LCA integration tools, it proposes new approaches for the treatment of environmental data and the establishment of a reference functional unit, as well as a possibility of methodological model for LCA within the BIM environment, by using existing and consolidated software with no need to develop or implement new evaluation tools.

\section{REFERENCES}

[1] Basbagill, J., Flager, F., Lepech, M. \& Fischer, M., Application of life-cycle assessment to early stage building design for reduced embodied environmental impacts. Building and Environment, 60, pp. 81-92, 2013.

[2] Lawson, B., Partridge, H. \& Gelder, J., Assessing the Environmental Impact of Building Materials. PRO 1, RAIA Environment Design Guide: Redhill, Australia, 1995.

[3] Brahme, R., Mahdavi, A., Lam, K.P. \& Gupta, S., Complex building performance analysis in the early stages of design, IBPSA. Proceedings of Seventh International IBPSA Conference, Rio de Janeiro, Brazil, 13-15 Aug. 2001, pp. 661-668. 
[4] Bank, L.C., McCarthy, M., Thompson, B.P. \& Menassa, C.C., Integrating BIM with system dynamics as a decision-making framework for sustainable building design and operation. First International Conference on Sustainable Urbanization (ICSU 2010), Hong Kong, China, Dec. 15-17, 2010. http://dx.doi.org/10.1.1.455.1368

[5] Ilhan, B. \& Yaman, H., Green building assessment tool (GBAT) for integrated BIMbased design decisions. Automation in Construction, 70, pp. 26-37, 2016.

[6] Creswell, J.W., Research Design. Qualitative, Quantitative, and Mixed Approaches, SAGE Publications: Singapore.

[7] Yohanis, Y.G. \& Norton, B., Including embodied energy considerations at the conceptual stage of building design. Proceedings of the Institution of Mechanical Engineers, Part A: Journal of Power and Energy, 220(3), p. 271e88, 2006.

[8] Gluch, P. \& Baumann, H., The life cycle costing (LCC) approach: A conceptual discussion of its usefulness for environmental decision-making. Building and Environment, 39(5), p. 571e80, 2004.

[9] Lee, K., Tae, S. \& Shin, S., Development of a life cycle assessment program for building (SUSB-LCA) in South Korea. Renewable and Sustainable Energy Reviews, 13(8), p. 1994e2002, 2009.

[10] Bribian, I.Z., Uson, A.A. \& Scarpellini, S., Life cycle assessment in buildings: Stateof-the-art and simplified LCA methodology as a complement for building certification. Building and Environment, 44(12), p. 2510e20, 2009.

[11] McGraw-Hill Construction, Green BIM, SmartMarket Report, 2010. http://bradleybim.fileswordpress.com $/ 2011 / 05 /$ mhc greenbim smartmarket report 2 010.pdf. Accessed on: 15 Sep. 2015.

[12] Wang, W., Zmeureanu, R. \& Rivard, H., Applying multi-objective genetic algorithms in green building design optimization. Building and Environment, 40(11), p. 1512e25, 2005.

[13] Hauglustaine, J. \& Azar, S., Interactive tool aiding to optimise the building envelope during the sketch design. IBPSA Conference, Rio de Janeiro, Brazil, 2001.

[14] Coley, D. \& Schukat, S., Low-energy design: Combining computer-based optimization and human judgment. Building and Environment, 37(12), p. 1241e7, 2002.

[15] Jrade, A. \& Jalaei, F., Integrating building information modelling with sustainability to design building projects at the conceptual stage. Build Simul, 6(4), pp. 429-444, 2013.

[16] Kovacic, I., Waltenbereger, L. \& Gourlis, G., Tool for life cycle analysis of facadesystems for industrial buildings. Journal of Cleaner Production, 130, pp. 260-272, 2016.

[17] Bueno, C. \& Fabricio, M.M., Application of Building Information Modelling (BIM) to perform Life Cycle Assessment of Buildings. Pós. Revista do Programa de PósGraduação em Arquitetura e Urbanismo da FAUUSP, 23, pp. 96-121, 2016.

[18] BuildingSMART, Data Dictionary. http://buildingsmart.org/standards/standardslibrary-tools-services/data-dictionary/. Accessed on: 25 Jan. 2017.

[19] Chartered Institution of Building Services Engineers (CIBSE), Product Data Templates. http://www.cibse.org/knowledge/bim-building-information-modelling/ product-data-templates. Accessed on 25 Jan. 2017.

[20] Bueno, C. \& Fabricio, M.M., Integrating Life Cycle Assessment and Building Information Modelling: An Overview. Euro-ELECS 2015 - $1^{\text {st }}$ Latin-American and European Conference on Sustainable Buildings and Communities, Guimarães, Portugal, 2015. 
110 Building Information Modelling (BIM) in Design, Construction and Operations II

[21] EC-JRC, European Commission: Joint Research Centre, International Reference Life Cycle Data System (ILCD) Handbook - General guide for Life Cycle Assessment Detailed guidance, 2010.

[22] Lemaire, S., Chevalier, J., Guarracino, G. \& Humbert, H., Using the French EPDs to compare and to choose building products. CIB World Building Congress, Construction for Development, Cape Town, 21-25 May 2007.

[23] Chevalier, J.L. \& Le Teno, J.F., Requirements for an LCA-based model for the evaluation of the environmental quality of building products. Building and Environment, 31(5), pp. 487-491, 1996.

[24] Peng, C., Calculation of a building's life cycle carbon emissions based on Ecotect and building information modeling. Journal of Cleaner Production, 112, pp. 453-465, 2016.

[25] Antón, L.A. \& Díaz, J., Integration of Life Cycle Assessment in a BIM environment. Procedia Engineering, 85, pp. 26-32, 2014.

[26] Oti, A.H., Tizani, W., Abanda, F.H., Jaly-Zada, A. \& Tah, J.H.M., Structural sustainability appraisal in BIM. Automation in Construction, 69, pp. 44-58, 2016. 